\title{
Agile Project Management: Massive Open Online Networked Learning for Thai Education
}

\author{
Annop Piyasinchart and Namon Jeerungsuwan
}

\begin{abstract}
The purpose of the research study is to develop the agile project management model for management program that involve in the information communication and technology such as "Massive open online networked learning for Thai education". The model comes out from many article and research document reviewed in the area of Management principle; Deming's management (PDCA), Complex Adaptive System: CAS, PMI project management and 3 new agile project management: 1) eXtreme Project Management, 2) Agile Project Management: Creating Innovative Products, and 3) Project Management e-learning. The open-ended questions are then developed and used to interview selected targets, who have more than 10 years of experience in their career path. According to the in-depth interviews, the comments are then used to synthesize model named "SEED of WISDOM: Agile Project Management and sent back to the experts for model approval. SEED is the 4 main management concepts of the model which are Scheme, Execute, Evaluate and Develop. WISDOM is the 6 processes. The model is now implementing to manage the "Massive open online networked learning".
\end{abstract}

Index Terms-Agile project management, complex adaptive system, massive open online networked learning, waterfall project management.

\section{INTRODUCTION}

Emergence of new Information Communication Technology (ICT) will play a big role in any project management program. Current Management tools have not delivered an efficient methodology to catch up with the projects in which ICT plays the major role. Agile project management will facilitate flexible management methods which will lead to better utilization of technology and resources in educational projects. A traditional management planning phase is usually centered on technical aspects, but ignores human aspects (academics, teachers and students), so we need to handle the human aspects as well in project planning. There should be an effective and suitable project management methodology to handle those issues. We need a more flexible way to manage projects that involve fast developing technology. We need flexible rather than rigid project management for both objectives and for managing the staff involved in projects. Flexible project management leads to open minds, not just people following management orders. This encourages thinking about how to effectively obtain the desired outcomes. The scope and purpose of projects can be

Manuscript received March 1, 2014; revised May 4, 2014.

Annop Piyasinchart is with Information Communication and Technology for Education Faculty of Technical Education King Mongkut's Institute of Technology North Bangkok, Thailand (e-mail: mailpiyasin@gmail.com).

Namon Jeerungsuwan is with the Department of Educational Technology, Faculty of Technical Education, King Mongkut's University of Technology North Bangkok, Thailand (e-mail: namon2015@gmail.com). changed to meet the changing world as long as the outcomes are still aligned with the vision and mission of the organization.

A good example of a rapidly changing technology based project is the attempt to integrate tablet computer based learning in all schools for grades 1-12 in Thailand. The government implemented a much-publicized One Tablet Per Child (OTPC) scheme by distributing nearly one million tablets to all Grade 1 students at the start of the 2012 semester. For the new coming semester in 2013, new tablet models are released, with much more capability but cheaper, so the government must review the tablets specification and costing again. The tablet is only one of many elements in a mobile learning environment which is changing fast. The tablet is a powerful "last mile" link in the m-Learning system and the $\mathrm{m}$-Learning system itself is changing because of the emergence of the smart mobile environment which includes tablets, mobile phones and $3 \mathrm{G}$ or $4 \mathrm{G}$ high speed broadband internet. For success with the OTPC project, it is not enough to only select a quality tablet and deliver it on time to all students in grades 1-12. The tablet does not teach by itself. We also need to prepare for students and teachers, digital content, schools' internet and wireless environments in order for the tablets to deliver education content effectively and provide connectivity between students and teachers and online knowledge. The tablet project, OTPC, is also a part of the Massive Open Online Networked Learning in which ICT plays a big role in the success of the project. We need an "Agile project management" which has much more flexibility to maintain synchronization with the changing smart mobile learning environment.

\section{RESEARCH OBJective}

The purpose of the research study is to develop an Agile Project Management model to facilitate flexible project management programs so project outcomes can stay aligned with requirements even in rapidly changing environments such as those that involve ICT, for example "The Agile Project Management for Massive Open Online Networked Learning for Thai Education".

\section{RESEARCH HYPOTHESIS}

That "Agile Project Management" can be approved and adapted to rapidly change ICT environments in the "Massive Open Online Networked Learning for Thai Education"

\section{THEORETICAL FRAMEWORK}

There are two aspects of project. The first one, the output 
or process itself is related to information communication and technology, ICT, and the second one is nothing involving ICT. The Project Management Institute, PMI, [1] developed PMBOK which included their nine bodies of knowledge for project management, and which is implemented worldwide. According to PMI project management the project scope is the first item and it must be clear and well planned, in detail, from the beginning. After the scope is settled, a step by step plan is created called a task break down structure (TBS). The TBS is like a waterfall in that it is a one way process; as each step is completed and approved and flows on to the next below, It is quite difficult to go backwards up the steps to determine if changes in the environment will affect the ability to reach the desired outcome or if improvements can be made in prior steps. The process is traditionally one way and will go to the next step one by one the same way as with a waterfall. This style of project management (PM) is less effective for projects in which changing technology and environment have the potential to adversely affect the outcome of the project. In these cases, including the "Massive Open Online Networked Learning" system which has 3 key flexible features [2]. First, it opened for any learners to join the course. Second, course participants use the social network as collaborative learning tools. Third, the system is unlimited for the number of learners. The authors propose the theoretical frame work, Fig. 1, as a frame work to develop the new model of "Agile Project Management" which is based on the three foundation principles for PM: 1) the standard code of conduct for all management, plan do check act, PDCA, from the Deming circle [3]. 2) Complex Adaptive System, CAS [4], which explains how a group of animals such as fishes, bees, ants and birds can be regrouped after something interferes with their group shaping, and 3) PMBOK from PMI. These principles are adapted into three Agile Project Management techniques: 1) "eXtreme Project Management" [5]. DeCarlo describes successfully using this method in software development projects; 2) "Agile Project Management: Creating Innovative Products" [6], Highsmith describes implementing new product development project using Agile; 3) "Project Management e-Learning" [7]. Shackelford implemented an e-learning project using adapted agile methods.

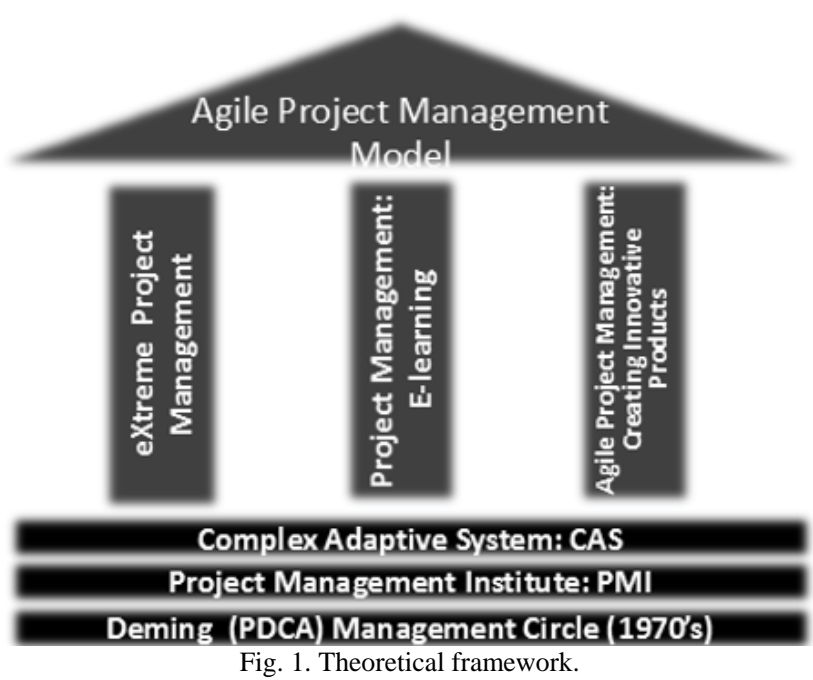

Agile Project Management is now also widely implemented in industrial projects. It has some distinguishing differences and underlying assumptions from traditional Project Management as follows: [8].

- Remains flexible with the rapid changing technology yet conforms to customer value.

- The success of a project is aligned with the satisfaction of the client even if the project team must change things during project development.

- Project break down is not on tasks and outcomes fixed at a project beginning, but tasks are changed iteratively as needed when client requirements change. Delivery is in small increments.

- Teams work by collaboration both within the team and between interested parties.

- Face to Face open information communication is emphasized.

- Builds a human team not a mechanical team (Agile Organic CAS) and uses simple rules for self-control; only light touches are used from outside.

- Needs agile vigilance: adaptive leadership not a project controller

According to the theoretical framework in Fig. 1, the authors developed the first Agile Project Management Model which is shown in Fig. 2.

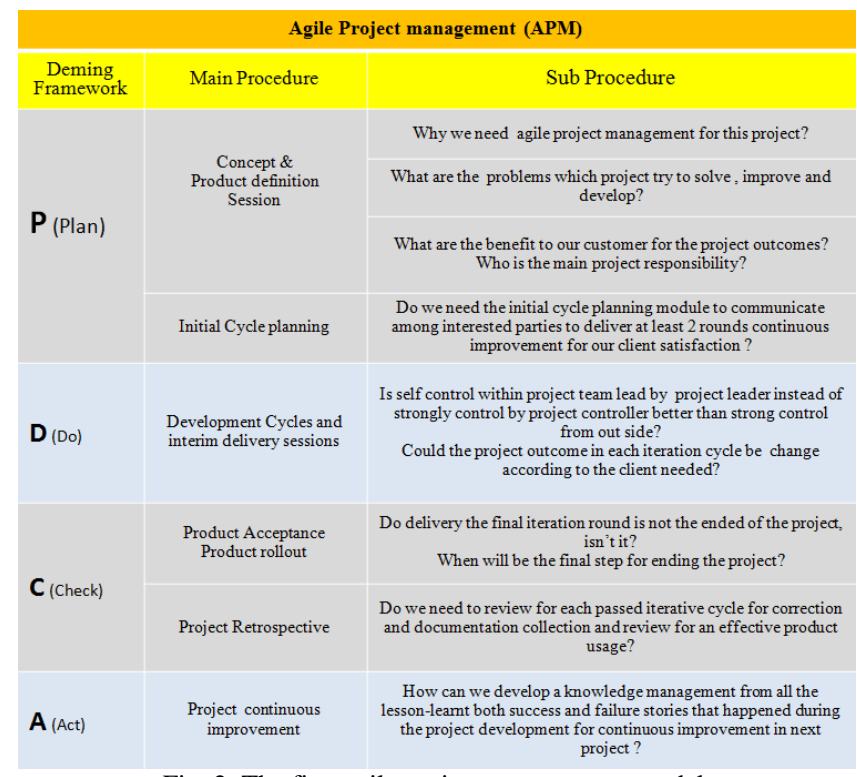

Fig. 2. The first agile project management model.

\section{ReSEARCh Methodology}

According to the literature review, the authors developed the agile project management model. Then we did the in-depth interviews with 2 groups of project management experts who have at least 10 years of experience in managing online learning projects or other technology related projects for revision and comment. Group 1 was six project management experts in online learning and technology related projects from the academia. Group 2 was five project management experts in e-training and technology related projects from private sector, and public organizations. The authors used the information gathered from the in-depth interviews to adjust the model then went back to the 2 groups for model approval. Summation of the interview data has been shown in Fig. 3. 


\section{RESEARCH OUTCOMES}

According to the 12 expert in-depth interview results, they agreed on the applicability of the Agile Project Management Model created by the authors. Even more one expert is now running the Enterprise Resource Planning, ERP, software project development under the Agile Project Management methodology. Eight experts already use a project management style which is similar to Agile PM. Twelve experts agreed that two different projects, unrelated and related technologies, require different project management styles for achieving the satisfaction of the interested parties. Usually for a related technology project like Massive Open
Online Networked Learning for Thai Education, there are no clear final outputs among the interested parties because no one can completely explain the clear picture of final products or services. In this case outcomes not outputs should be clear and rigid for all the interested parties especially for the project execution teamwork who have the responsibility to go in the right direction which delivers the project outcomes. Having this clear vision the team has been loosely controlled by outsiders, and this team can manage itself. There are frequently communications within the team and among the interested parties. The summation of 2 group in-depth interviews is shown in Fig. 3.

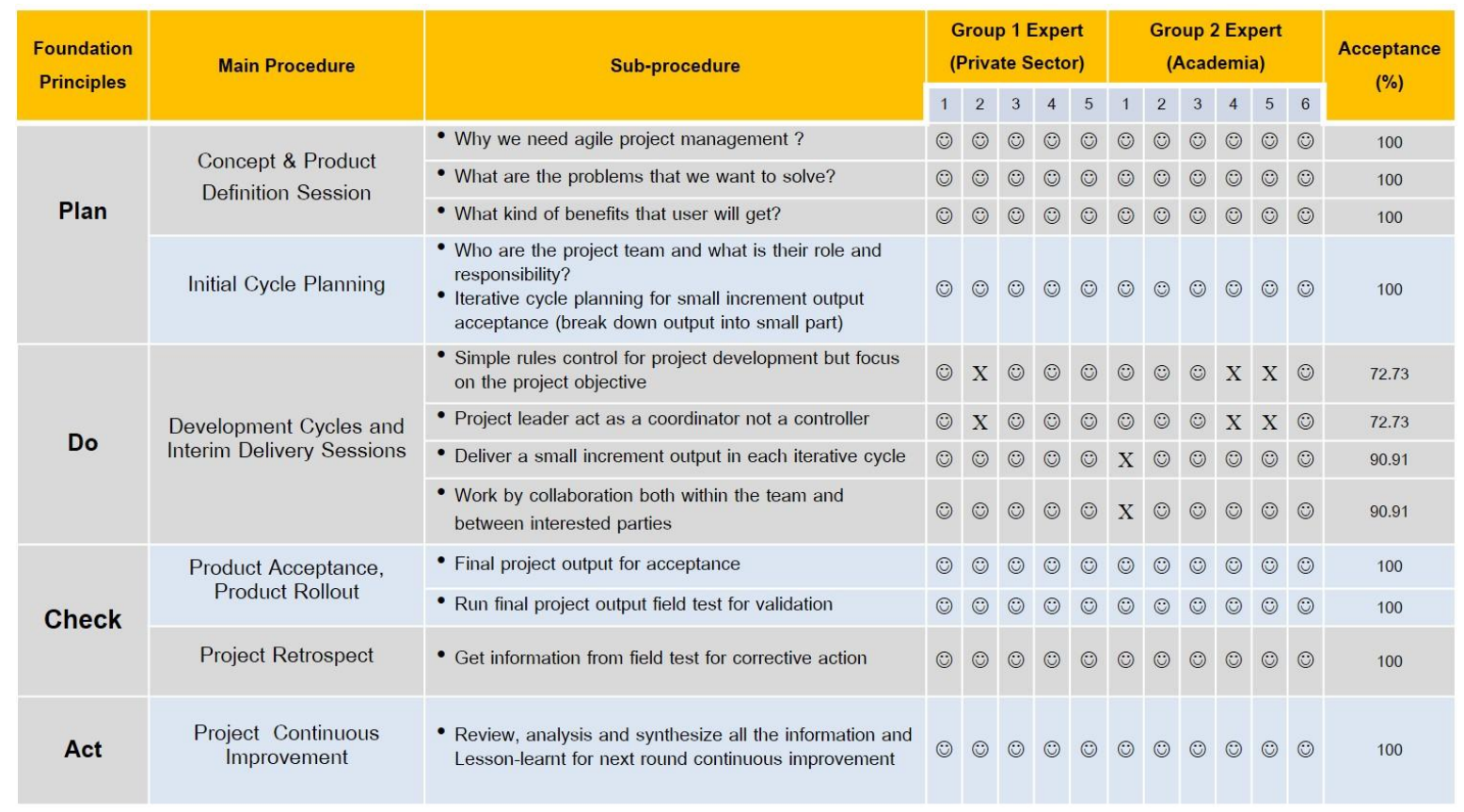

:) $\rightarrow$ Agree with the model idea $\quad \mathrm{X} \rightarrow$ Disagree with the model idea

Fig. 3. The summarized in-depth interviews data from 11 project management experts.

\begin{tabular}{|c|c|c|c|c|}
\hline \multicolumn{5}{|c|}{ Agile Project management $($ APM $) \rightarrow$ SEED of WISDOM APM Development } \\
\hline \multicolumn{2}{|c|}{ Deming Framework } & \multicolumn{2}{|c|}{ Main Procedure } & \multirow{2}{*}{ Sub Procedure } \\
\hline Original & Synthesize & Original & Synthesize & \\
\hline \multirow{4}{*}{$\mathbf{P}_{\text {(Plan) }}$} & \multirow{4}{*}{$\mathbf{S}$ (scheme) } & \multirow{3}{*}{$\begin{array}{l}\text { Concept \& } \\
\text { Product definition } \\
\text { Session }\end{array}$} & \multirow{3}{*}{$\begin{array}{l}\text { What are Project Concept } \\
\text { \& Definition? }\end{array}$} & Why we need agile project management for this project? \\
\hline & & & & $\begin{array}{l}\text { What are the problems which project try to solve, improve and } \\
\text { develop? }\end{array}$ \\
\hline & & & & $\begin{array}{l}\text { What are the benefit to our customer for the project outcomes? } \\
\text { Who is the main project responsibility? }\end{array}$ \\
\hline & & Initial Cycle planning & $\begin{array}{l}\text { Iterative cycle } \\
\text { Planning }\end{array}$ & $\begin{array}{l}\text { Do we need the initial cycle planning module to communicate } \\
\text { among interested parties to deliver at least } 2 \text { rounds continuous } \\
\text { improvement for our client satisfaction? }\end{array}$ \\
\hline \multirow{2}{*}{$\mathbf{C}_{\text {(Check) }}$} & \multirow{2}{*}{$\mathbf{E}$ (evaluate) } & $\begin{array}{l}\text { Product Acceptance } \\
\text { Product rollout }\end{array}$ & $\begin{array}{l}\text { Delivery Final Products for } \\
\text { Acceptance \& Rollout } \\
\text { Project }\end{array}$ & $\begin{array}{l}\text { Do delivery the final iteration round is not the ended of the } \\
\text { project, isn't it? } \\
\text { When will be the final step for ending the project? }\end{array}$ \\
\hline & & Project Retrospective & $\begin{array}{l}\mathbf{O}_{\text {perate }} \\
\text { Retrospective }\end{array}$ & $\begin{array}{c}\text { Do we need to review for each passed iterative cycle for } \\
\text { correction and documentation collection and review for an } \\
\text { effective product usage? }\end{array}$ \\
\hline $\mathbf{A}_{\text {(Act) }}$ & D (develop) & $\begin{array}{l}\text { Project continuous } \\
\text { improvement }\end{array}$ & $\begin{array}{l}\text { Manage Guide Line for } \\
\text { Continuous Improvement }\end{array}$ & $\begin{array}{l}\text { How can we develop a knowledge management from all the } \\
\text { lesson-learnt both success and failure stories that happened } \\
\text { during the project development for continuous improvement in } \\
\text { next project? }\end{array}$ \\
\hline
\end{tabular}

Fig. 4. SEED of WISDOM for agile project management synthesizing table. 


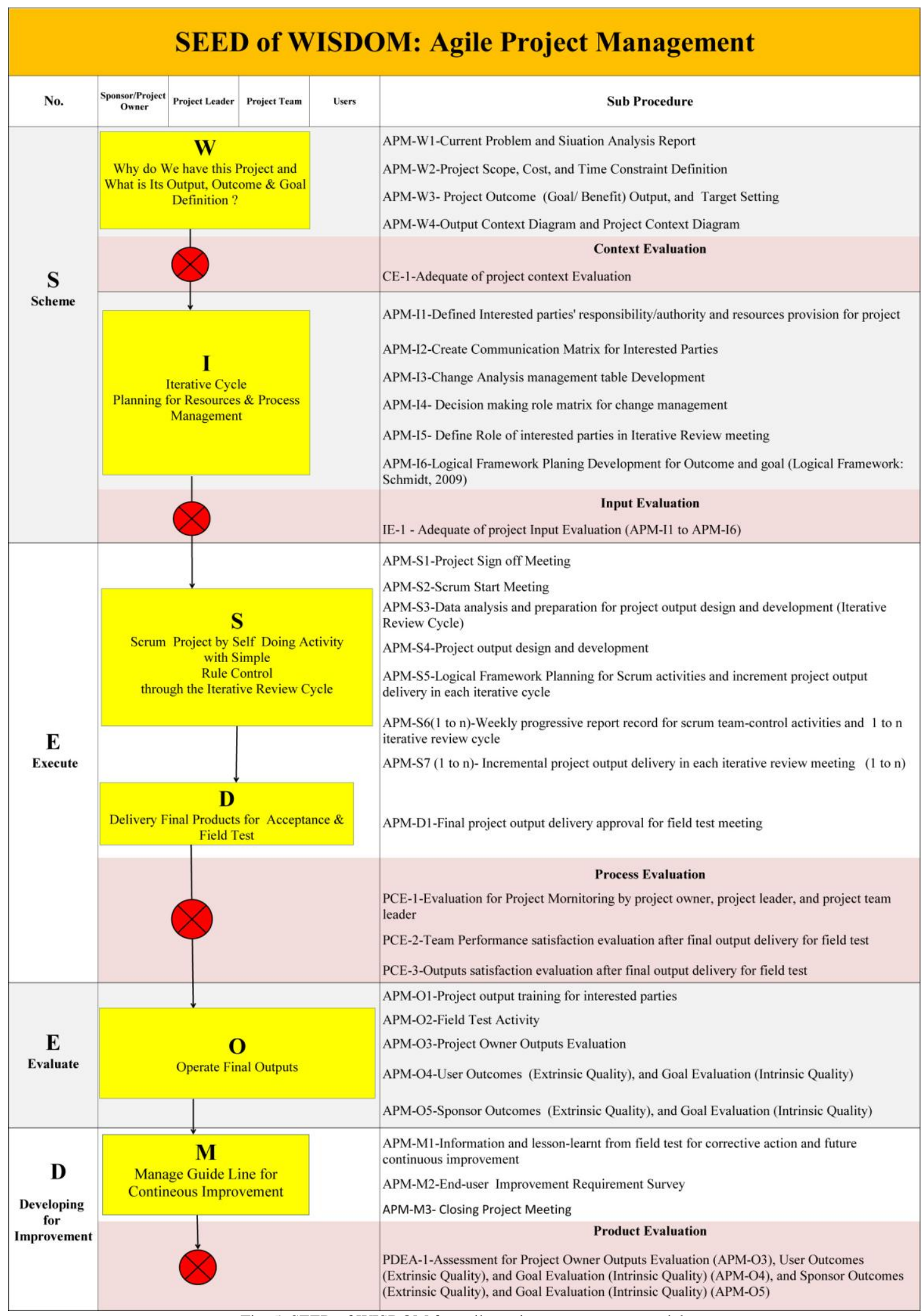

Fig. 5. SEED of WISDOM for agile project management model.

\section{A. Group 1}

The first experts agreed that applying the Agile PM model to "Massive Open Online Networked Learning for Thai Education" is appropriate and gives us the idea to do a proactive training in Agile PM to the proposed project team and for all interested parties because Agile PM is quite new to Thailand. The second expert also agreed with the applicability of Agile PM to Massive Open Online Networked Learning for Thai Education, but suggested the authors include much more detail in the model to help those unfamiliar with it. The third expert agreed with the model, he also referred to at least 2 big successful ICT government projects, the online tax revenue payment and the issuing ID smart card system. He suggested that successful Agile project management needs a qualified self-disciplined team and strong intention leader as a facilitator otherwise it might fail The last 3 experts also agreed with the applicability of the model and also pointed out that human resources are also 
another fast changing factor, like technology, and in some cases are much more complicated than our expectations. One expert suggested that a flexible team management for Thai people might be a problem he added that we need to have some controlling system. One expert gave us a notice for a government project which always has a rigid scope of work that could not be changed and might not be applicable for Agile Project Management.

\section{B. Group 2}

One expert who has experience in a mega project, reducing the water lost by enhancing ICT, gave an experience about spending much time in planning phase. However, during the execution phase there was an unexpected job during the night time that was never mentioned in the planning phase, which lead to many problems for the project. He also agreed with the importance of project communication, a weekly basis is his suggestion. Three experts agreed that for Agile Project Management we need the project manager who has high communication skill. Since the project outputs do not stand still, but easy to move, so it is the project manager's responsibility to communicate to the interested parties for better understanding, in case the project scope has to be changed.

One expert suggested us to develop the software to enhance the Agile Project Management capability. Another expert is already applying the Agile Project Management in a new product development project, the digital water meter development. He also expressed the idea that rapidly changing environments are not only happening in technology, but with people as well. One of the experts, the CEO of a Software Industry Promotion Agency (Public Organization), gave an interesting example. He informed us that his role is a facilitator to support software companies. Owing to many projects that he must be involved in, it is quite impossible for him to know all the details of each project.

The authors have reviewed and synthesized the information from the in-depth interviews to propose the "SEED of WISDOM for Agile Project Management model" transformation table in Fig. 4 and the final "SEED of WISDOM for Agile Project Management Model" which is already approved by the 10 experts in Fig. 5 .

\section{SUGGESTIONS FROM THE RESEARCH}

Twelve project management experts agreed that the "SEED of WISDOM model" could be appropriately applied to the Massive Open Online Networked Learning for Thai Education, but two obstacles may block the effectiveness of an Agile PM. These are:

1) Cultural issues might limit the ideal of individuals supervising themselves (i.e. personal responsibility) from functioning well, and; 2) The bureaucratic system of the government sector might make it difficult to change to an Agile PM like system of project management in a large government project. It is common in government projects to close a project that meets all the items in the Terms of Reference (TOR) or specifications, yet the final outcome would go unused because it is already obsolete.
In conclusion, Agile Project Management is a good and applicable project management tool for technology related projects which are run by private sector or medium and small government projects where rapidly changing technology is an issue. The author is now implementing the "SEED of WISDOM Agile Project Management to develop the project "Massive Open Online Networked Learning for Thai Education".

\section{ACKNOWLEDGMENT}

The authors would like to thank King Mongkut's University of Technology North Bangkok for the research fund.

\section{REFERENCES}

[1] Project Management Institute, A Guide to the Project Management Body of Knowledge, $3^{\text {rd }}$ ed., Newtown Square: Project Management Institute, 2004.

[2] R. Kob. (2011). A pedagogy of Abundance or a Pedagogy to Support Human Beings? Participant Support on Massive Open Online Courses. [Online]. http://www.irrodl.org/index.php/irrodl/article/view/1041

[3] J. M. Juran, Juran's Quality Handbook, $5^{\text {th }}$ ed., New York. McGraw-Hill, 2000.

[4] J. H. Holland. (2012). Complex Adaptive System. [Online]. Available: http://www.jstor.org/discover

[5] D. DeCarlo. (2010). A Guide to eXtreme Project Management [Online]. http://www.projectconnections.com/articles/decarlo.html,

[6] J. Highsmith, Agile Project Management, $2^{\text {nd }}$ edition, Boston: Pearson Education Inc., 2010.

[7] B. Shackelford, Project Management e-Learning, $3^{\text {rd }}$ edition, Alexandria: American Society for Training \& Development, 2005.

[8] CCPACE. (2011). Agile Project Management. [Online]. Available: http://www.ccpace.com

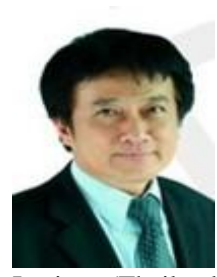

Annop Piyasinchart is currently a doctoral degree student, information communication and technology for Education Faculty of Technical Education King Mongkut's Institute of Technology North Bangkok, Thailand

$\mathrm{He}$ is the CEO of DBIC Co., Ltd., an online learning solution service company in Thailand. He is also the board of directors of Management System Certification Institute (Thailand). He received his master degree in business administration and bachelor degree in chemical engineer from Chulalongkorn University, Thailand.

Mr. Piyasinchart is a local expert in Total Quality Management System (TQM) of Association for Overseas Technical Scholarship (AOTS), a senior international advisor of the Institute of APEC Collaborative Education (IACE), and the president of APEC Learning Collaborative Entrepreneur Committee (ALCoBEC) Thailand.

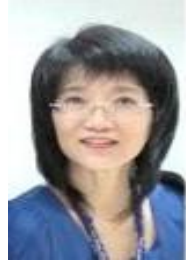

Namon Jeerungsuwan is currently a full time deputy professor at the Department of Educational Technology, Faculty of Technical Education, King Mongkut's University of Technology North Bangkok, Thailand. She received her doctoral degree in instructional design and development from the University of South Alabama and her master's degree in educational media from Western Oregon University. She also received the award of the Royal Thai Government Scholarship and the award of Kappa Delta Phi while she was pursuing her doctoral degree Dr. Jeerungsuwan has held a position of the director of Ph.D. Program in information and communication technology for education since 2011. She was the head of the Department of Educational Technology, Kmutnb, during 2002-2006. 